\title{
O SONO NORMAL
}

\author{
THE NORMAL SLEEP
}

Regina Maria França Fernandes

Docente. Departamento de Neurologia, Psiquiatria e Psicologia Médica. Faculdade de Medicina de Ribeirão Preto - USP.

Correspondência: Disciplina de Neurologia. Departamento de Neurologia, Psiquiatria e Psicologia Médica. Hospital das Clínicas da Faculdade de Medicina de Ribeirão Preto - USP.

Avenida Bandeirantes, 3900. Campus Universitário Monte Alegre. CEP 14048-900 Ribeirão Preto, SP, Brasil. Fones: 016-36022546 / Fax: 016-36330866 / email: rmfferna@fmrp.usp.br.

Fernandes RMF. O sono normal. Medicina (Ribeirão Preto) 2006; 39 (2): 157-168.

RESUMO: O sono é um estado fisiológico cíclico, caracterizado no ser humano por 5 estágios fundamentais, que se diferenciam de acordo com o padrão do eletrencefalograma (EEG) e a presença ou ausência de movimentos oculares rápidos (rapid eye movements : REM), além de mudanças em diversas outras variáveis fisiológicas, como o tono muscular e o padrão cardiorespiratório. O EEG mostra alentecimento progressivo com o aprofundamento do sono sem movimentos oculares rápidos (Não-REM) e atividade rápida dominante de baixa voltagem, semelhante à da vigília, durante o sono REM. Um ciclo noturno previsível de 90 minutos marca a variação entre os 4 estágios do sono Não-REM para o sono REM, descrevendo uma arquitetura característica, com proporções definidas de cada estágio, que variam segundo a faixa etária. Um bio-ritmo neuroquímico acompanha as variações circadianas do chamado ciclo vigília-sono, com mudanças específicas da temperatura corporal e da secreção de diversos hormônios e neurotransmissores, relacionados aos diferentes estágios do sono e da vigília. O conhecimento dos aspectos fisiológicos e das variações patológicas deste ciclo complexo deu margem ao desenvolvimento da Medicina do Sono e compõe as bases do estudo dos distúrbios do sono na prática clínica.

Descritores: Sono; fisiologia. Fases do Sono. Sono REM. Ritmo Circadiano. Movimentos Oculares.

\section{1- INTRODUÇÃO}

O sono é um estado fisiológico especial que ocorre de maneira cíclica em uma grande variedade de seres vivos do reino animal, tendo sido observados comportamentos de repouso e atividade, compondo um ciclo vigília-sono rudimentar, em animais tão inferiores na escala zoológica como os insetos. Mas, a caracterização do sono por parâmetros eletrofisiológicos já foi feita em anfíbios, répteis e mamíferos, além do ser humano.

Definir o sono não é tarefa simples, seja sob o ponto de vista fisiológico, seja com base na descrição comportamental do indivíduo que dorme. Assim, como veremos adiante, algumas fases do sono mostram características eletrofisiológicas semelhantes às da vigília (no eletrencefalograma, no padrão respiratório, na presença de movimentos oculares e de alguns movimentos corporais), diferindo de outras etapas do sono, em que há completa quietude e elevado teor de ondas lentas no eletrencefalograma (EEG). Isto evidencia a natureza não homogênea de diferentes etapas do sono, quando avaliado por registros poligráficos, dificultando uma definição simplista deste estado.

Do mesmo modo, podemos dizer que, em sono, os indivíduos apresentam-se imóveis, ou com um re- 
pertório limitado de movimentos, os quais são de natureza involuntária, automática, sem propósitos definidos. A reatividade a estímulos auditivos, visuais, tácteis e dolorosos é reduzida ou abolida em relação à vigília, particularmente em fases de sono profundo, sendo necessário o aumento da intensidade do estímulo para trazer o indivíduo de volta à vigília, o que nem sempre é observado, mesmo sob estimulação intensa, particularmente nas crianças. Durante o sono, o indivíduo mantém-se de olhos fechados ou entreabertos e não mostra interação produtiva com o ambiente. Nestes termos, o sono pode ser visto como um estado similar ao coma, especialmente nos casos de coma de menor profundidade, em que não há comprometimento das funções cardio-respiratórias. Assim, o grande diferencial entre tais estados, à simples observação do ser que dorme, é a característica de reversão espontânea e mais ou menos programada ao longo do tempo do estado de sono para a vigília, o que não é o caso do coma.

A evolução do conhecimento sobre o sono, tanto em âmbito experimental, quanto na prática clínica, foi possível a partir do domínio sobre o registro das ondas cerebrais através do EEG, o que permitiu a discriminação objetiva entre vigília relaxada e sono, bem como, entre os seus diferentes estágios. Tal conhecimento culminou, ao longo do século XX, com o desenvolvimento de registros poligráficos, valendo-se de outras variáveis funcionais além do EEG, para a documentação da fisiologia do sono e a melhor caracterização dos seus distúrbios, com o nascimento da Medicina do Sono.

\section{2- DADOS HISTÓRICOS}

O primeiro registro das ondas cerebrais na superfície do crânio foi obtido pelo neuropsiquiatra alemão, Hans Berger, em 1929 (apud Niedermeyer E, $2005)^{1}$, marcando o início da eletrencefalografia, que foi incorporada à prática clínica à partir de 1930 . Berger já havia ressaltado as diferenças entre as ondas cerebrais registradas na vigília e durante o sono, no qual dominavam ondas lentas e de amplitude crescente, conforme se dava seu aprofundamento. Assim, do ponto de vista do EEG, o sono era vinculado a uma atividade elétrica cerebral mais lenta e de padrão sincronizado, em comparação com a atividade mais dessincronizada e de baixa voltagem da vigília. Estes dados foram reforçados pelos trabalhos básicos desenvolvidos em gatos por Frederick Bremer, em 1935 e $1936^{2}$. O autor fez duas preparações nestes animais, uma com secção da parte inferior do bulbo, denominada encéphale isolé, e outra com secção em nível mesencefálico, logo acima da origem dos nervos oculomotores, a que denominou cerveau isolé. $\mathrm{Na}$ primeira preparação, foi observada manutenção de uma atividade elétrica cortical dessincronizada, com ritmos rápidos e irregulares, em resposta a estímulos visuais, olfativos, vestibulares, auditivos e músculo-cutâneos. No cerveau isolé, os estímulos ficaram restritos às esferas olfativa e visual, não sendo suficientes para elicitar um padrão de vigília no EEG, que mostrava atividade lenta sincronizada, como num sono profundo. Assim, o autor postulou que o sono seria a reprodução de um estado de deaferentação cortical reversível. Ao mesmo tempo, estudos em controles normais e pacientes com queixas diversas relativas ao sono estavam sendo realizados por Kleitman e colaboradores, na Universidade de Chicago, desde o ano de $1938^{2}$. Estes autores faziam diversas tomadas do EEG durante a noite, na tentativa de avaliar os padrões encontrados no decorrer da mesma, em associação com o comportamento observado do indivíduo. Kleitman passou a se interessar pelo registro dos movimentos oculares, juntamente com o EEG, buscando um outro marcador de profundidade do sono. A razão disto era o grande campo elétrico produzido no escalpo pelos movimentos dos globos oculares, muito superior a qualquer atividade motora detectável na superfície do crânio. Em 1951, Kleitman designou a função de observar os movimentos corporais e oculares durante o sono a seu aluno de graduação, Eugene Aserinsky. Estes pesquisadores observaram a presença de movimentos oculares em momentos nos quais o paciente parecia dormir profundamente, em associação com movimentos corporais e irregularidade respiratória, inferindo a possível associação de tais episódios com a ocorrência de sonhos. Posteriormente, esta observação foi comprovada através do registro dos movimentos oculares pelo eletro-oculograma (EOG) e do tono muscular na região submentoniana, o qual se mostrava extremamente reduzido, ou abolido, nestes períodos em que o indivíduo freqüentemente referia estar sonhando, caso fosse despertado. Assim, Aserinsky e Kleitman caracterizaram pela primeira vez a ocorrência de um estágio particular durante o sono em que ocorriam os sonhos, sendo marcado pela presença de movimentos oculares, além de atonia ou hipotonia muscular, o que foi documentado na revista Science, em $1953^{3}$. Somente dois anos mais tarde, tais 
autores estabeleceram diferenciação entre movimentos oculares do sono, numa publicação de $1955^{4}$, discriminando os movimentos oculares rápidos (do Inglês: Rapid Eye Movements, ou REM), associados com o estágio de sono em que ocorriam sonhos, dos movimentos oculares lentos, registrados no início do sono, ou fase I, não-REM. A publicação de 1953 sugerindo a existência do sono REM não mereceu crédito do mundo científico, uma vez que o sono era classicamente associado à presença de atividade lenta $\mathrm{e}$ sincronizada no EEG e a idéia de um sono profundo de padrão eletrográfico rápido, dessincronizado, parecia inconcebível. Aserinsky e Kleitman, associados a Dement, persistiram em sua pesquisa, desenvolvendo estudos poligráficos sistemáticos do sono, com registro contínuo durante a noite. Demonstraram a marcada hipotonia do sono REM, documentando a ausência do reflexo $\mathrm{H}$ nesta fase e diferenciando-a definitivamente da vigília, do ponto de vista eletroneuromiográfico. Em 1957, Dement, Aserinsky e Kleitman descreveram a existência de um ciclo básico de sono noturno, caracterizado pela ocorrência de sono REM a cada 90 minutos, após uma sequiência dos estágios do sono Não-REM, repetindo-se 5 a 6 vezes durante a noite, o que resultou na publicação do trabalho seminal destes autores com a clássica descrição do sono REM ${ }^{5}$.

O estudo poligráfico do sono, batizado de polissonografia, foi inicialmente aplicado a quadros de sonolência excessiva diurna vinculada especialmente à hipótese de Narcolepsia. Entretanto, em 1965, a descrição da síndrome da Apnéia Obstrutiva do Sono, por dois grupos independentes, (Gastaut, Tassinari e Duron, na França; ${ }^{6}$ Jung e Kuhlo, na Alemanha) ${ }^{7}$, abriu um campo vasto no conceito de Medicina do Sono, sendo este um dos distúrbios do sono mais prevalentes, ainda na atualidade. Na verdade, esta síndrome foi caracterizada em pacientes com quadros clínicos já de longa data conhecidos pelos pneumologistas e genéricamente citados como Síndrome de Pickwick. O conhecimento sobre os distúrbios do sono levou à formação de sociedades médicas internacionais, devotadas à Medicina do Sono e à elaboração das classificações internacionais dos distúrbios do sono, surgindo a primeira em $1990^{8}$, seguida por outra em $1997^{9}$ e, finalmente, pela mais atual classificação, proposta no ano de $2005^{10}$. Com esta breve história sobre a evolução do conhecimento referente ao sono e sua aplicação na Medicina, passaremos a uma descrição mais objetiva de aspectos relevantes sobre a fisiologia do sono no ser humano.

\section{3- ESTÁGIOS DO SONO}

A caracterização das fases do sono pode ser feita com base em 3 variáveis fisiológicas que compreendem o EEG, o EOG e o eletromiograma (EMG) submentoniano (Figura 1). Através delas são caracterizados 2 padrões fundamentais de sono: sem movimentos oculares rápidos (NREM) e com movimentos oculares rápidos (REM). O sono NREM é composto por 4 etapas em grau crescente de profundidade, os estágios I, II, III e IV. No sono NREM, há relaxamento muscular comparativamente à vigília, porém, mantém-se sempre alguma tonicidade basal. O EEG exibe aumento progressivo de ondas lentas, conforme se avança do estágio I para o estágio IV do sono NREM.

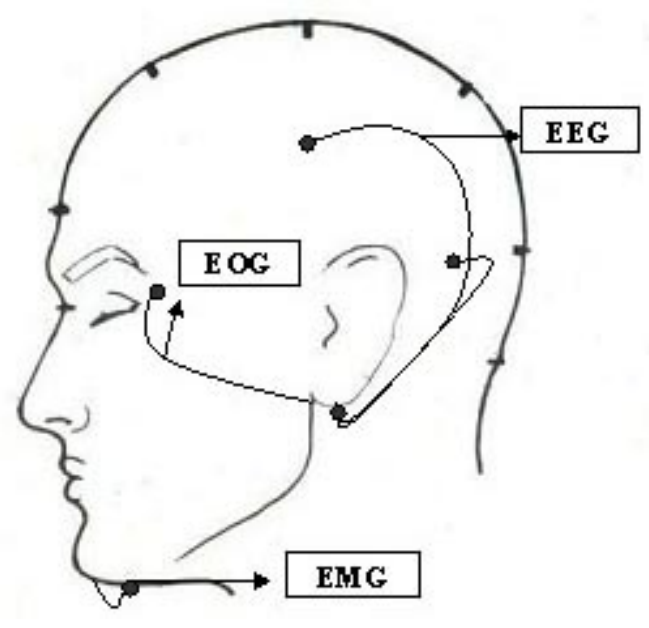

Figura 1: Parâmetros essenciais para o estadiamento do sono. EEG: eletrencefalograma; EOG: eletro-oculograma: EMG: eletromiograma submentoniano.

Durante a vigília, predomina o ritmo alfa, uma atividade elétrica cerebral em freqüência de 8 a 13 ciclos por segundo (Figura 2), que passa a se fragmentar, surgindo em menos de 50\% dos trechos analisados, conforme se inicia a sonolência superficial, a qual já se caracteriza como estágio I do sono NREM. Em seguida, o ritmo alfa desaparece, dando lugar a uma atividade mista nas faixas de frequiência teta (4 a 7 ciclos por segundo) e beta (acima de 13 ciclos por segundo), com poucos componentes delta de média amplitude, surgindo as Ondas Agudas do Vértex, que marcam a sonolência profunda, ainda designada de estágio I do sono NREM (Figura 3). Com o aprofundamento para o estágio II, além de um certo aumento 
no componente de ondas delta no traçado, surgem os Fusos de Sono (surtos de atividade rítmica de 12 a 14 ciclos por segundos, com duração média entre 1 e 5 segundos) e os Complexos K (ondas lentas bifásicas de alta amplitude, acompanhadas, ou não, de fusos do sono, ambos registrados na região do vértex e frontal sagital) (Figura 4). Outros grafoelementos de destaque são os chamados POSTS (do inglês, Positive Occipital Sharp Transients of Sleep: elementos transientes positivos agudos occipitais do sono), que podem se manter em todos os estágios. As fases III e
IV compõem o chamado sono delta ou de ondas lentas, devido ao elevado teor de ondas na faixa de frequiência delta $(0,5$ a 3,5 ciclos por segundo) de alto potencial (> 70 microvolts). No estágio III, o EEG é ocupado por 20 a $50 \%$ destas ondas (Figura 5), que passam a se registrar em mais de $50 \%$ do traçado no estágio IV (Figura 6), sendo esta a fase mais profunda do sono NREM. As características gerais do sono NREM são resumidas no Quadro I. Mais detalhes sobre estes componentes podem ser vistos no capítulo deste simpósio referente à Polissonografia.

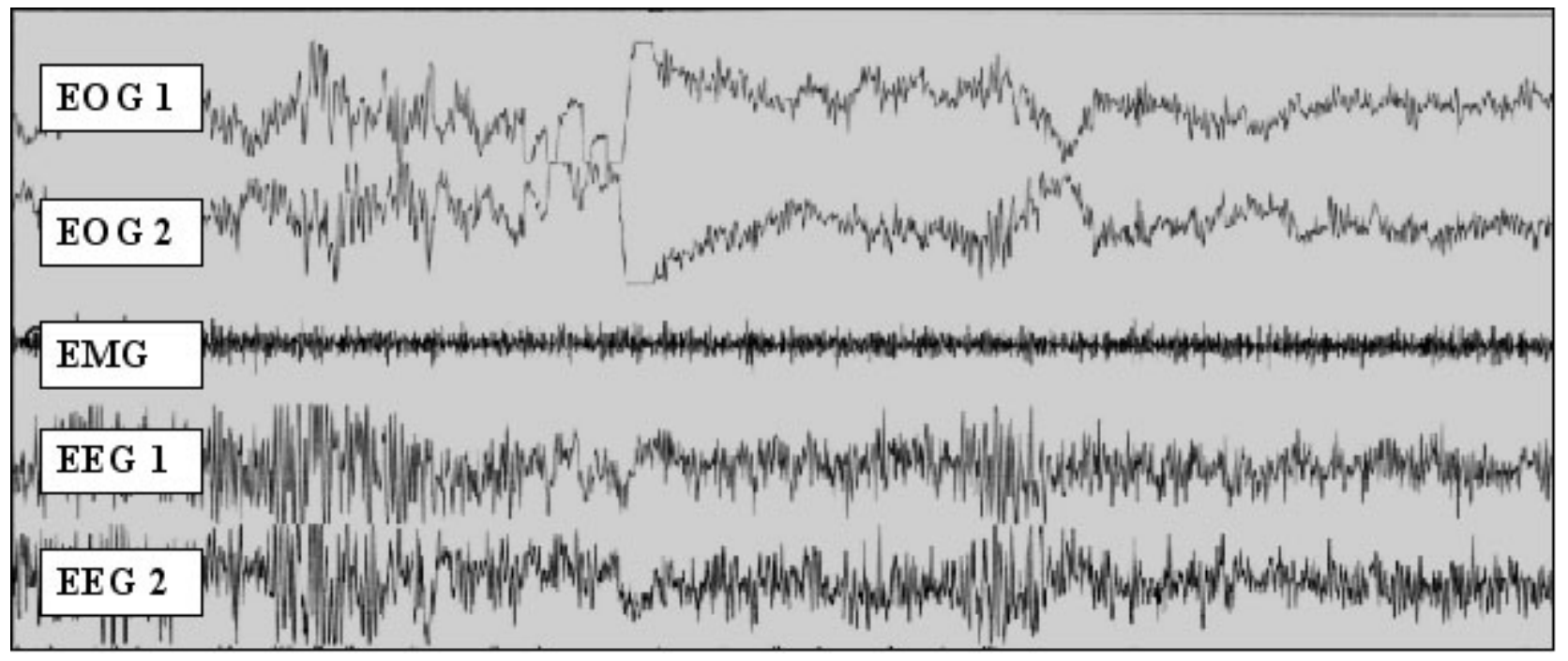

Figura 2: Trecho de 30 segundos de vigília em traçado polissonográfico. Observe o predomínio de ritmo alfa nos canais de EEG. EOG-1 = Eletro-oculograma do olho esquerdo; EOG-2 = Eletro-oculograma do olho direito; EMG = eletromiograma submentoniano; $E E G$ = canais de eletrencefalograma

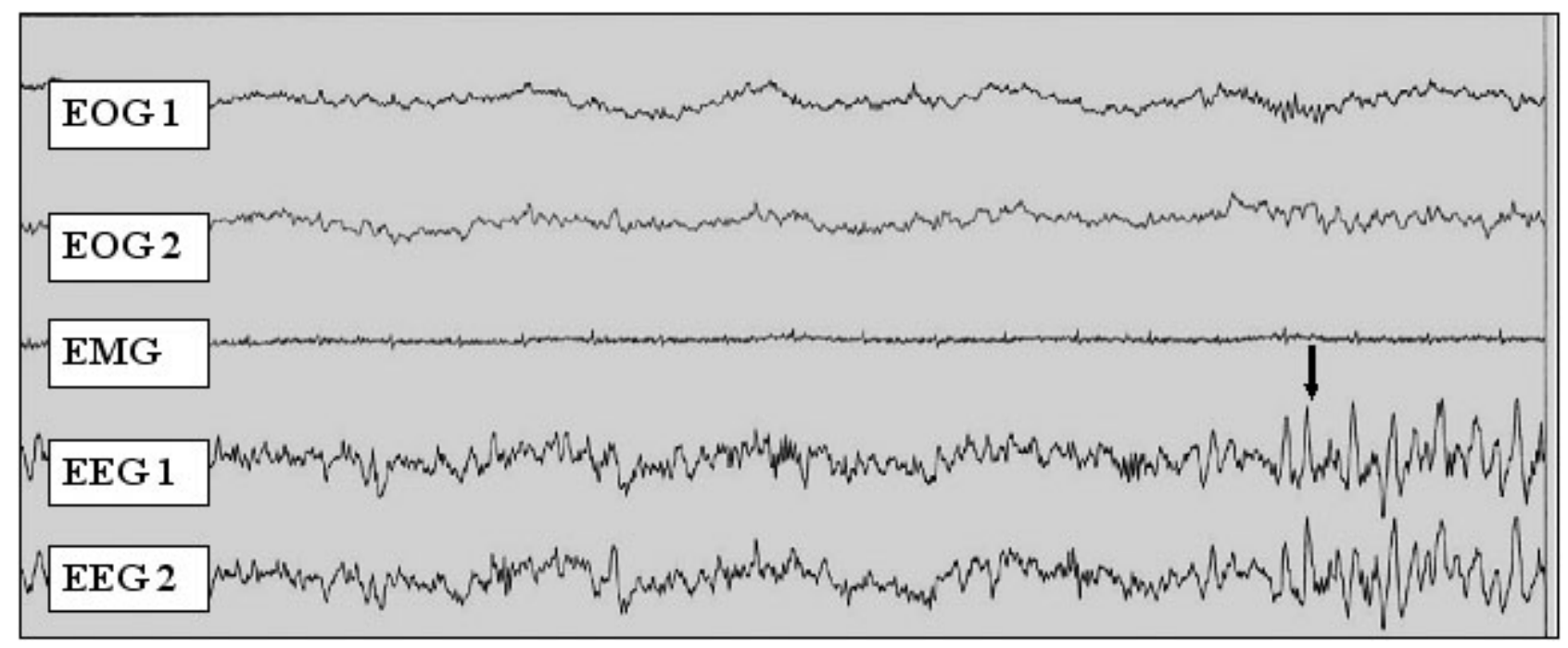

Figura 3: Trecho de derivações EEGráficas (EEG1 e EEG2) em estágio I do sono NREM. EOG-1 e EOG-2= Eletro-oculograma do olho esquerdo e direito; EMG = eletromiograma submentoniano; Seta = Ondas Agudas do Vértex. 


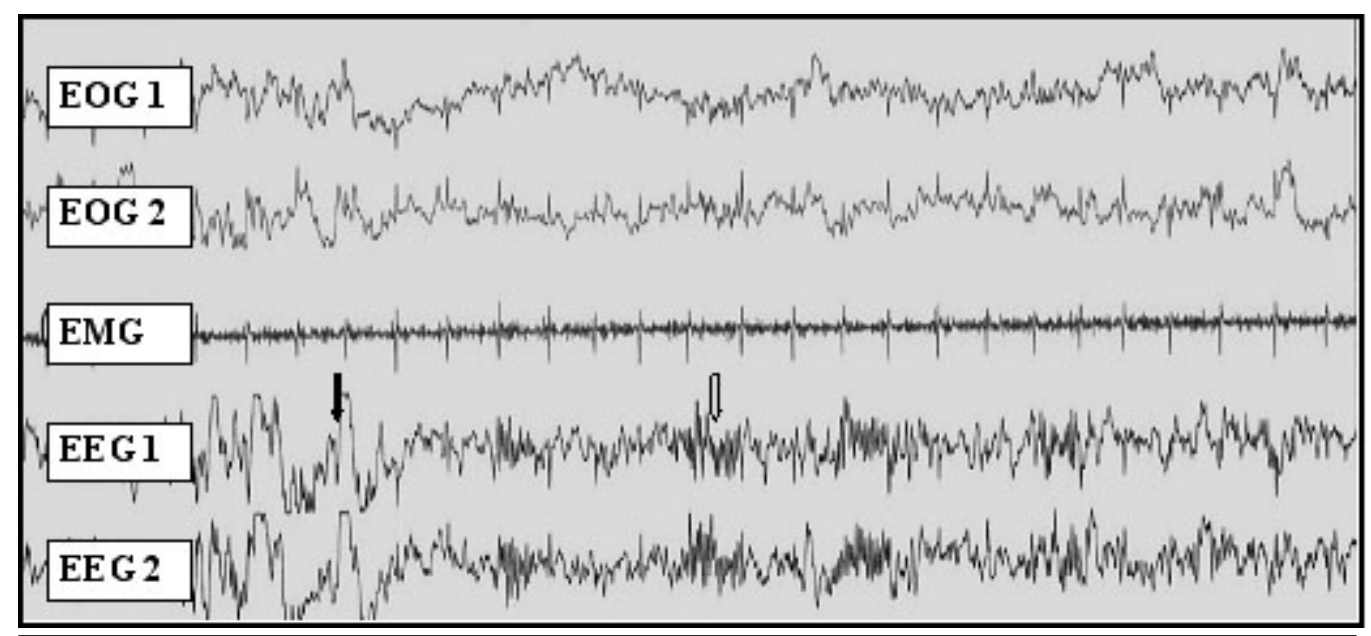

Figura 4: Trecho de derivações EEGráficas (EEG1 e EEG2) em estágio II do sono NREM. EOG-1 e EOG-2 = Eletro-oculograma do olho esquerdo e direito; EMG = eletromiograma submentoniano; Seta escura = Complexo $\mathrm{K}$; Seta clara = fuso de sono.

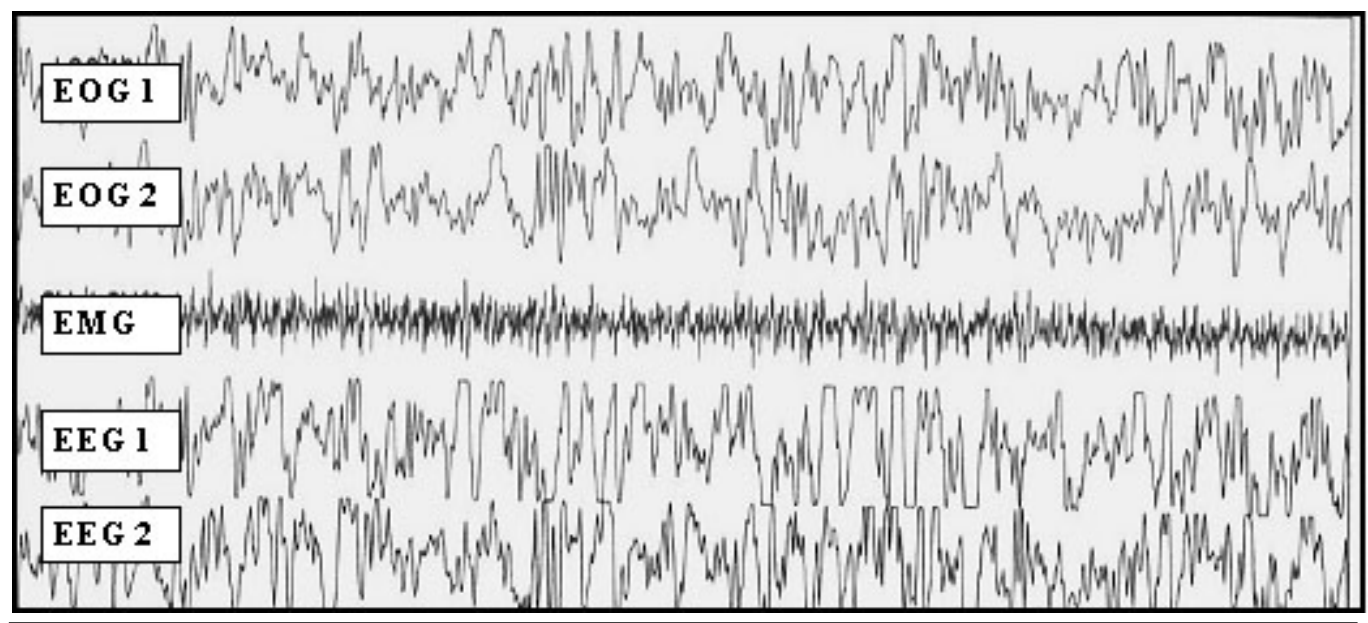

Figura 5: Trecho de derivações EEGráficas (EEG1 e EEG2) em estágio III do sono NREM. EOG-1 e EOG-2 = Eletro-oculograma do olho esquerdo e direito; EMG = eletromiograma submentoniano. A atividade do EEG gera ondas amplas em $20 \%$ a $50 \%$ de traçado.

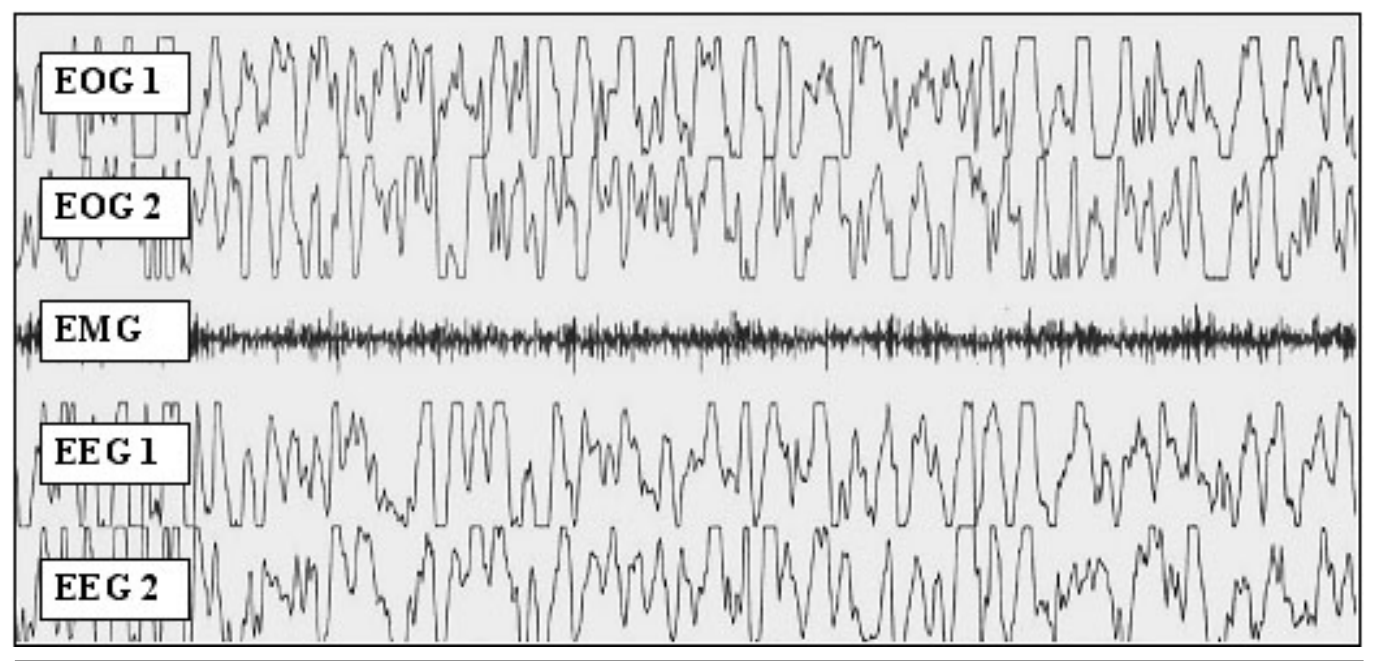

Figura 6: Trecho de derivações EEGráficas (EEG1 e EEG2) em estágio IV do sono NREM. EOG-1 e EOG-2 = Eletro-oculograma do olho esquerdo e direito; EMG = eletromiograma submentoniano. A atividade do EEG gera ondas amplas em mais de $50 \%$ do traçado. 


\section{Quadro I: Caracteristicas gerais do som NREM}

- Relaxamerto muscular com manuteņão do tômus

- Progessiva redux̧ão de movimertos corporais

- Aumento progressivo de ondas lentas no EEG (20 a $50 \%$ de ondas delta em sono III; mais de $50 \%$ em sono IV)

- Ausência de movimentos oculares rápidos

- Respiração e Eletrocardiograma regulares

O sono REM recebe também as denominações de sono paradoxal e de sono dessincronizado. Apesar de ser um estágio profundo no tocante à dificuldade de se despertar o indivíduo nesta fase, exibe padrão eletrencefalográfico que se assemelha ao da vigília com olhos abertos, ou mesmo do sono NREM superficial (estágio I), sendo este um dos seus aparentes paradoxos. Além disto, apesar da atonia muscular que acompanha este estágio, observam-se movimentos corporais fásicos e erráticos, de diversos grupamentos musculares, principalmente na face e nos membros, bem como, emissão de sons. Ou seja, mesmo em meio a inibição motora, há liberação fásica de atividade muscular de localização multifocal, outro aparente paradoxo. O padrão predominantemente rápido e de baixa voltagem das ondas cerebrais neste sono justifica o termo dessincronizado para o mesmo (Figura 7). Encontram-se nesta fase as chamadas ondas em dente de serra, atividade rítmica na faixa delta a teta (habitualmente, 2 a 5 ciclos/segundo) de aspecto serrilhado, que são uma das marcas do EEG no sono REM. As características gerais do sono REM são descritas no Quadro II. No sono REM, a atividade metabólica, avaliada por métodos funcionais e de medida de fluxo sangüíneo cerebral encontra-se aumentada em comparação com a da vigília, em diversas áreas do encéfalo. Isto demonstra que o sono não pode ser entendido necessáriamente como um estado de repouso, para economia energética, em comparação com a vigília, como se postulava inicialmente.

\section{Quadro II: Caracteristicas gerais do somo REM}

- Hipotoria ou Atoria Muscular

- Movimentos fásicos e mioclorias multifocais / emissão de sors

- Movimentos oculares rápidos

- EEG com predomírio de ritmos rápidos e de baixa voltagem

- Respiração e Eletrocardiograma irregulares

- Sorhos

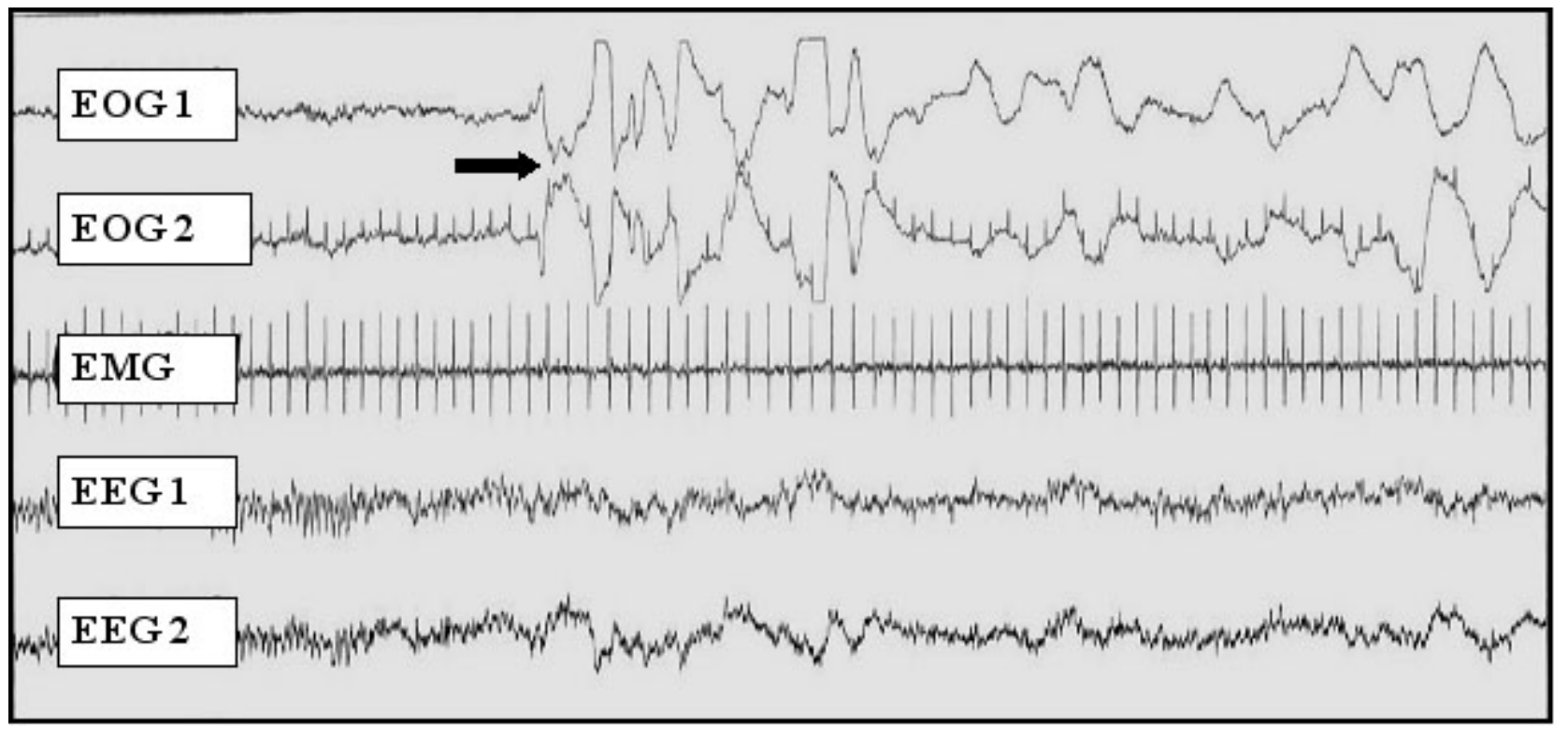

Figura 7: Trecho de derivações EEGráficas (EEG1 e EEG2) em sono REM. EOG-1 = Eletro-oculograma do olho esquerdo; EOG-2 = Eletrooculograma do olho direito; EMG = eletromiograma submentoniano. A atividade elétrica no EEG é constituida por ondas de baixa voltagem. Seta $=$ movimentos oculares rápidos. 
Movimentos oculares de padrão lento e ondulante marcam o estágio I do sono NREM (Figura 3), enquanto os movimentos rápidos do sono REM são salvas de abalos amplos e multidirecionais dos globos oculares (Figura 7). A respiração é regular à partir da fase II do sono NREM, atingindo-se máxima regularidade cardio-respiratória no sono profundo de ondas lentas, fase IV. Por outro lado, o sono REM é marcado por irregularidades do padrão respiratório, com episódios de bradipnéia, alternados com taquipnéia e pausas centrais, inferiores a 10 segundos, em que há interrupção transitória do esforço respiratório. Uma irregularidade fisiológica na freqüência cardíaca comumente acompanha a variabilidade respiratória do sono REM. Neste, ocorre também tumescência peniana e clitoriana, que não são documentadas em registros polissonográficos de rotina.

Os sonhos são uma manifestação de conteúdo visual, auditivo, verbal, somestésico e emocional, em geral, com enredo seqüencial, passível de rememoração pelo paciente e de ativação autonômica, relacionada ao seu conteúdo (Exemplo: ativação simpática em sonhos que elicitam sensações de medo ou apreensão). Pode haver emissão de sons ou de fala durante os mesmos e a possibilidade de recapitulação dos sonhos é variável, dependendo da duração do período REM em que ocorrem (maior quanto mais longo o período), ou de seu significado do ponto de vista afetivo, referente a memórias relevantes do indivíduo e, ainda, na dependência de ocorrer um despertar consciente no decorrer ou no final do período REM em que o sonho se manifesta.

A exata função e significado dos sonhos ainda não pôde ser explicada de forma objetiva pela medicina, havendo, contudo, evidências de que ele seja importante na reorganização sináptica e processamento de funções plásticas, referentes à homeostase em áreas cerebrais relacionadas com memória, aprendizado e funções psíquicas. A interpretação dos sonhos, baseada nas relações causais entre determinantes internos e externos da vida psíquica do indivíduo e do chamado inconsciente, foi e ainda é motivo de grandes especulações e pesquisa clínica na área de Psiquiatria. Porém, tal aprofundamento foge ao escopo deste texto.

\section{4- ARQUITETURA DO SONO}

Em condições normais, um indivíduo inicia o sono noturno pelo estágio I do sono NREM, após um tempo de latência aproximada de 10 minutos. Uma latência muito baixa para início do sono NREM pode ocorrer nos indivíduos privados de sono, ou muito cansados, sendo também encontrada em síndromes que cursam com sono não reparador, como os distúrbios respiratórios do mesmo. Após uns poucos minutos em sono I, há o aprofundamento para o sono II, em que se torna mais difícil o despertar do indivíduo. Após 30 a 60 minutos, instala-se o sono de ondas lentas, respectivamente, os estágios III e IV, com interpenetrações de ambos no decorrer desta etapa mais profunda do sono NREM. Passados aproximadamente 90 minutos, acontece o primeiro sono REM, que costuma ter curta duração no início da noite (5 a 10 minutos), completando-se o primeiro ciclo NREM-REM do sono noturno (Figura 8). A saída do sono REM pode se fazer com intrusão de microdespertares ( 3 a 15 segundos de duração), sem um despertar completo do paciente, mudando-se para o estágio I e, em seguida, o estágio II do sono NREM, ou passando diretamente para este último estágio e, em seguida, aprofundando-se novamente nos estágios III e IV. Desta forma, cumpremse cerca de 5 a 6 ciclos de sono NREM-REM, durante uma noite de 8 horas de sono. Os despertares podem ocorrer a qualquer momento durante o sono, a partir de qualquer estágio, seja de forma espontânea, ou eventualmente provocada por fatores extrínsecos

\section{HIPNOGRAMA}

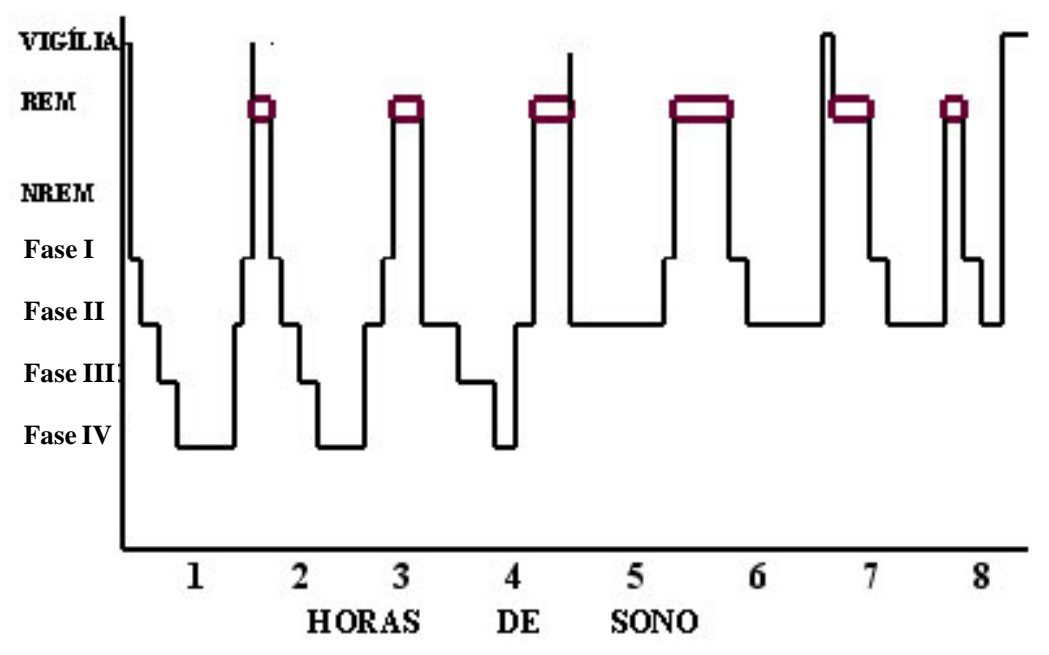

Figura 8: Hipnograma do sono noturno 
(exemplo: ruído) ou eventos patológicos (como apnéias, conforme citado em capítulos seguintes). É comum que o indivíduo não tenha consciência destes despertares, especialmente quando de curta duração e não relacionados com eventos anormais (pesadelos, quadros respiratórios, etc...).

Na primeira metade da noite, ocorre sono de ondas lentas, estágios III e IV, em alternância com os demais estágios, como se pode observar no hipnograma da Figura 9. Porém, o sono delta, III e IV, tende a não mais ocorrer na segunda metade da noite e no amanhecer, quando há alternância entre os estágios I, II e REM, especialmente nos adultos. Em crianças até o período escolar, é comum a ocorrência de sono de ondas lentas ainda no final da madrugada, em geral, de menores duração e profundidade do que na primeira metade da noite. Nos idosos, pode haver mudanças na arquitetura do sono, de tal forma que o sono IV não mais se registra, havendo redução de sono III e aumento do número de despertares noturnos. Isto explica em parte porque alguns idosos são mais sonolentos durante o dia, em vista de mudanças na fisiologia do sono com a idade, sem relação necessária com patologia definida. Por outro lado, esta não é uma regra geral e muitos idosos podem manter uma arquitetura relativamente preservada como no padrão do adulto. Além disto, a avaliação cuidadosa costuma identificar a presença de alterações psíquicas (depressão, ansiedade), físicas (dores, distúrbios respiratórios do sono, problemas urinários, quadros neurológicos) provocando a fragmentação do sono do idoso, com aumento dos despertares e superficialização do sono. Assim, este conceito geral sobre mudanças do hipnograma com o envelhecimento deve ser aceito com ressalvas.

As proporções de cada estágio do sono durante uma noite típica, sem fenômenos anormais e com duração compatível com as necessidades do indivíduo são: 5 a $10 \%$ de estágio I, 50 a $60 \%$ de estágio II, 20 a $25 \%$ de estágios III e IV, em conjunto, e 20 a $25 \%$ de estágio REM. A chamada eficiência de sono compreende a proporção do tempo em que um indivíduo dorme, em relação ao tempo total e que se manteve na cama para o sono noturno. É considerada normal a partir de $85 \%$. Entretanto, uma eficiência de $100 \%$ é rara, considerando-se a presença de despertares noturnos, mesmo que inconscientes.

A necessidade diária de sono varia de acordo com a idade e de forma individual. O recém-nascido prematuro, até a idade pós-concepcional de 32 semanas, apresenta apenas o sono REM. Ao nascer, este ainda predomina sobre o NREM, que aumenta progressivamente em proporções no decorrer dos primeiros meses de vida, até atingir as proporções do adulto, por volta do segundo ano. O neonato dorme cerca de $80 \%$ do período das 24 horas de um dia, intercalando a vigília de acordo com seu ciclo alimentar, mais ou menos a cada 3 ou 4 horas. No decorrer do primeiro ano, há aumento no tempo de vigília durante o dia e do

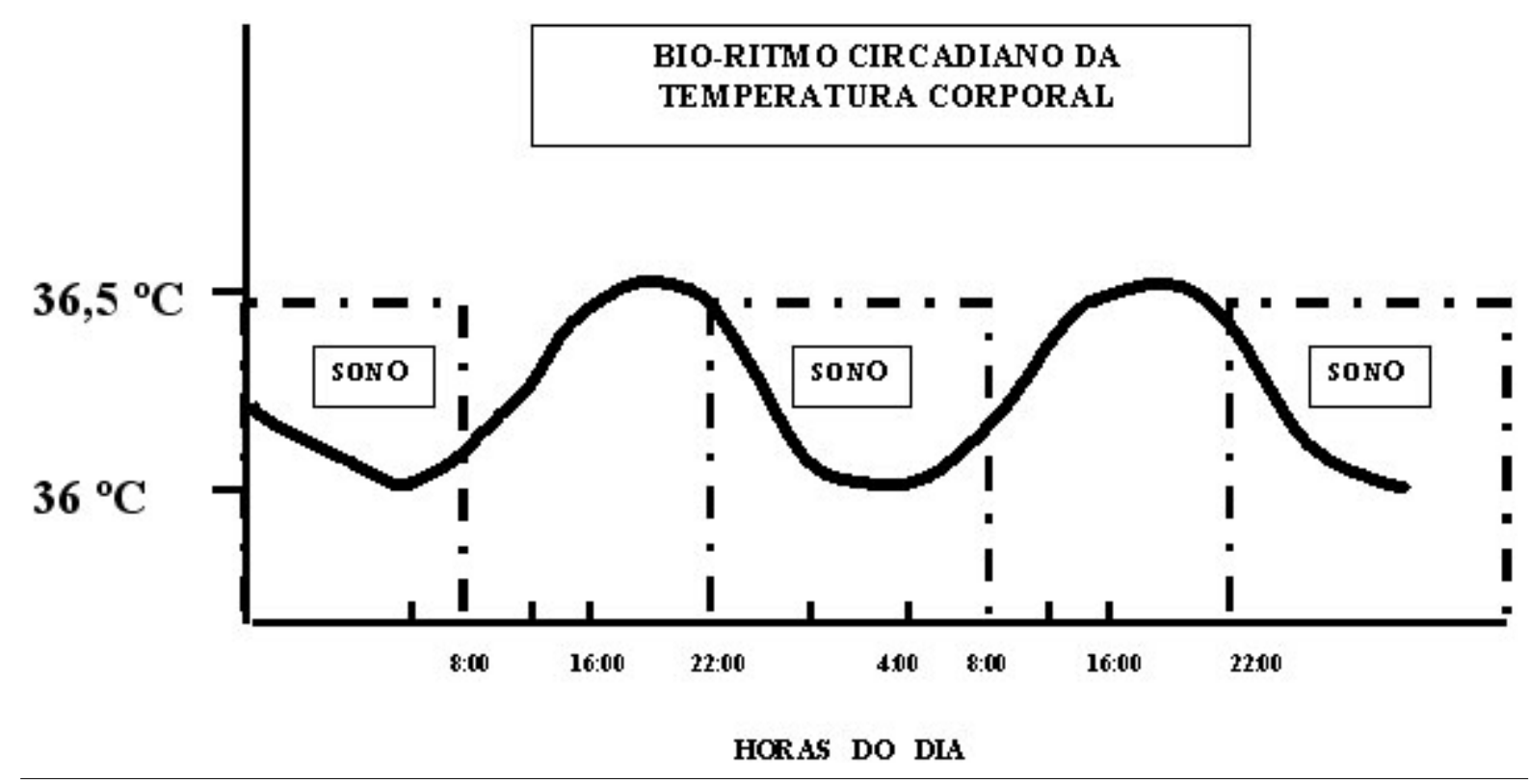

Figura 9: Curva de variação da temperatura corporal ao longo das 24 horas do dia. 
período de sono sustentado à noite. O lactente dorme 13 a 15 horas por dia, contando com uma média de dois períodos de sono diurno; o pré-escolar dorme entre 12 e 13 horas, habitualmente com um período de sono diurno. A necessidade diária de sono da criança escolar situa-se entre 10 e 12 horas, no período noturno, havendo grande resistência ao sono no decorrer do dia, nesta faixa etária. Isto resulta em dificuldade de se observar sonolência excessiva diurna em crianças escolares com distúrbios que reduzem a quantidade total de sono. Nestes contextos, mais comumente elas manifestarão irritabilidade, déficits de atenção e de aprendizado do que franca sonolência diurna. A necessidade diária de sono do adolescente situa-se em torno de 8 e 10 horas, sendo este mais propenso ao sono no período da tarde do que o escolar. Entre os adultos, a necessidade diária de sono varia de 5 a 8 horas, em média. A maioria dos adultos não se sente completamente refeito de sua necessidade de sono com menos de 7 horas por dia, embora as demandas socio-culturais habitualmente o impinjam a dormir menos do que sua necessidade endógena. Pessoas com necessidade de sono muito reduzida como 3 horas/dia, sem qualquer comprometimento físico, mental ou intelectual, são raras.

A privação total do sono em uma noite leva ao fenômeno de rebote de sono, nas duas noites seguintes: assim, há tendência a aumento nas proporções de sono REM, na noite seguinte à privação, e aumento do sono NREM na segunda noite, voltando-se à arquitetura normal do sono noturno somente na terceira noite. Isto é algo problemático para trabalhadores noturnos, que mudam de turno freqüentemente, sem um esquema fixo. Eles podem exibir uma arquitetura de sono sempre conturbada, além de sintomas de cansaço, irritabilidade, alterações de intelecto e sonolência excessiva diurna, alternada com insônia.

\section{5- CRONOBIOLOGIA E CICLO CIRCADIANO}

A capacidade do indivíduo de adequar seu ciclo de sono e vigília ao ciclo noite-dia da terra é guiada por diversos elementos externos e internos que interagem para a manutenção de um ciclo circadiano (do latim: circa $=$ em torno de; dies $=$ do dia). Assim, a luminosidade e o calor do dia, a escuridão e a redução da temperatura ambiental à noite, as variações de incidência de luz no decorrer do dia, os relógios, os sons das cidades e de animais (galo, pássaros, etc...) são elementos que nos condicionam a manter um rit- mo de atividade alternada com repouso e intercalada com funções de ingestão e eliminação, dentro do padrão circadiano.

Experimentos com voluntários humanos em ambientes dos quais são retirados todos estes elementos indicadores do ciclo dia-noite mostram que, no ser humano, o ciclo endógeno situa-se em torno de 25 horas, não obedecendo necessariamente as 24 horas do dia geológico. Tais ambientes experimentais eram inicialmente cavernas com acampamento improvisado com luz artificial, ou, mais modernamente, apartamentos fechados e isolados de qualquer som ou luz externos, bem como, desprovidos de relógio, TV ou Internet, que possam dar pistas ao indivíduo sobre os horários do dia. Nesta situação, observa-se que os sujeitos começam a organizar suas atividades de modo a iniciar seu sono noturno com atraso de uma hora a cada dia, em relação ao dia anterior, perfazendo um período de 25 horas, a contar do momento do despertar após período de sono sustentado, correspondente ao sono noturno, até o próximo despertar. No final de um período de 25 dias, o sujeito entra novamente no horário em que começou o experimento. Este é o chamado ciclo livre ou free running cycle, como é citado na literatura em Inglês. Algumas pessoas têm dificuldades de sincronizar seu ciclo circadiano de repouso-atividade, ou vigília-sono com o ciclo geológico e social, mesmo diante de todos os parâmetros de condicionamento encontrados no ambiente. Assim, têm um período de sono irregular, com tendência a sempre atrasar uma hora a cada dia em relação ao momento do início do sono noturno. Tal dificuldade, quando endógena e não provocada por má-higiene do sono, tem sido classificada como um distúrbio do ciclo circadiano, designado "ciclo diferente de 24 horas".

Do ponto de vista endógeno, o organismo humano apresenta ciclos complexos de secreção hormonal e de neurotransmissores, bem como, padrões de atividade de determinados centros encefálicos, que se acoplam aos sincronizadores externos para permitir uma variação do bio-ritmo de repouso e atividade, em sintonia com o ciclo circadiano da terra. Um dos centros encefálicos mais importantes nesta sincronização é o núcleo supra-óptico, no hipotálamo anterior, que recebe impulsos luminosos carreados pelo nervo óptico, tendo a luz como um dos elementos que controlam o funcionamento deste centro. Os estímulos luminosos também atuam sobre a glândula pineal, que secreta a melatonina, um neuro-hormônio implicado na cronobiologia do ciclo vigília-sono. A secreção de 
melatonina segue um padrão programado, influenciado pela luminosidade ambiental, com seu pico máximo nas primeiras horas da noite, participando da tendência do indivíduo a conciliar o sono. Este pico é considerado um dos "portões" de entrada no sono. Assim, se um indivíduo força o estado de vigília, lutando contra o sono neste momento propício, perde a entrada através deste portão determinado pelo pico de secreção de melatonina, tendo dificuldades de conciliação do sono após. Obviamente, a melatonina não é o único elemento determinante desta periodicidade do ciclo vigília-sono no ser humano, mas certamente é reconhecida como um dos neuro-hormônios mais importantes.

Alguns hormônios e neurotransmissores têm sua secreção vinculada ao ciclo vigília-sono, facilitando o estado de vigília ou o estado de sono. Assim, nas primeiras horas da manhã, há aumento da secreção do hormônio tireoideano, de cortisol e de insulina, que são facilitadores da vigília, seja por aumento da taxa metabólica para a iniciação das atividades do dia, ou indiretamente pelo aumento da glicemia e da utilização de glicose pelas células ${ }^{11}$.

O hormônio do crescimento tem seu pico de secreção durante o sono NREM de ondas lentas, assim como a testosterona. Distúrbios que levam à fragmentação do sono em crianças (como asma brônquica e distúrbios respiratórios do sono) podem ter repercussões negativas no crescimento pondo-estatural das mesmas. Também, os sintomas de disfunção erétil masculina encontrados no contexto da Síndrome da Apnéia Obstrutiva do Sono, embora de fisiopatogenia complexa, que também envolve ativação simpática repetitiva durante as apnéias e fatores psicogênicos, podem ter em parte relação com déficit de testosterona decorrente de privação crônica de sono. O hormônio antidiurético também tem seu pico de secreção noturna, o que, numa visão teleológica, pode se relacionar com a necessidade de se reduzir a produção de urina durante a noite, evitando-se o despertar causado pela plenitude vesical. Especula-se que crianças com enurese noturna idiopática possam ter imaturidade neste controle da secreção noturna do hormônio antidiurético. Alguns peptídeos produzidos no trato gastro-intestinal, durante o processo de digestão, como a colecistocinina e a bombesina, atingem a circulação sangüínea e são comprovadamente indutores do sono NREM. Isto explica em parte a sonolência pós-prandial, além da maré alcalina do sangue provocada pelo aumento da secreção gástrica.

Outros neuro-transmissores são importantes na indução do sono, como a hipocretina, ou orexina, a beta-endorfina, a encefalina, a dinorfina e a prostaglandina D2, e da vigília, como a substância P, o fator de liberação da corticotrofina (CRF), o fator de liberação da tireotrofina (TRF) e o peptídeo intestinal vasoativo (VIP). Maior aprofundamento neste tema foge aos objetivos deste texto ${ }^{11}$.

Dentre tantos mecanismos endógenos sincronizadores do ciclo vigília-sono, destaca-se a curva de variação da temperatura corporal interna. Esta sofre mudanças em torno de meio grau centígrado nas 24 horas, o que é suficiente para facilitar ou dificultar a ocorrência de sono, conforme se observa na Figura 9. Nas primeiras horas da manhã, a curva começa a ascender, facilitando a manutenção da vigília. A temperatura interna máxima é atingida no período da tarde, entre as 16:00 e 18:00 horas, começando a decair lentamente à partir do início da noite. Esta queda é facilitadora da conciliação do sono. Na madrugada, o indivíduo atinge a temperatura corporal interna mais baixa, o que é favorecedor do sono REM. Esta queda térmica ocorrerá mesmo que a pessoa se mantenha acordada em determinada noite. A seguir, à partir das 6:00 horas da manhã, a temperatura começa a ascender, facilitando o despertar matinal ${ }^{11}$.

Um indivíduo que mude subitamente para um fuso horário muito diferente terá que se ajustar do ponto de vista neuroquímico e da curva térmica a um novo bio-ritmo. Enquanto isto, tenderá a sentir sonolência excessiva em horários em que deveria estar desperto e insônia no período destinado ao sono. Um exemplo banal é a ocorrência de despertar, com sensação de calor, por volta das 2:00 da manhã, em indivíduos que viajaram de São Paulo para a Califórnia nos meses de verão do Brasil, quando há diferença de 6 horas entre os dois locais. Mesmo cansados do processo de viagem e atividades diárias, tais indivíduos tendem a despertar por volta das 2:00 horas da manhã, que corresponderia às 8:00 horas de seu horário original, em decorrência de elevação de temperatura corporal, pico de cortisol, de hormônio tireoideano e insulina neste horário. Por outro lado, existe grande chance destas pessoas sentirem sonolência insuportável por volta das 16:00 horas, que corresponderiam às 22:00 horas do seu horário original. Os sintomas decorrentes dos desajustes de fusos horários são considerados ainda mais intensos em viagens no sentido do leste. Isto ilustra o fato de que o ciclo vigília-sono é regido por bio-ritmo neuroquímico e funcional complexo, que não tolera desajustes abruptos e requer um tempo de adaptação às mudanças impostas por novos hábitos ou por grandes mudanças de fusos horários. 


\section{6- CENTROS ENCEFÁLICOS GERADORES DO SONO}

Em linhas gerais, o estado de vigília é promovido pela ativação constante do sistema reticular ascendente do tronco encefálico, em decorrência de estímulos diversos que adentram a formação reticular. Todos os estímulos somato-sensoriais, como o próprio fato do indivíduo estar em posição ereta, com a estimulação proprioceptiva característica, bem como, os estímulos visuais, auditivos, olfativos, gustativos e vestibulares, são carreados ao tálamo e ao córtex cerebral, promovendo a vigília. Outros centros que conduzem estimulação ao córtex promotora da vigília são: o hipotálamo posterior, que contém neurônios histaminérgicos, cuja inibição pelos anti-histamínicos induz ao sono; -o núcleo basal de Meynert e o núcleo septal, nas porções basais e anteriores do diencéfalo. A atividade tônica de neurônios catecolaminérgicos e colinérgicos da substância reticular ativadora ascendente modula a ativação de neurônios destes centros subcorticais e do córtex cerebral, promovendo a vigília.

O sono NREM, ou sincronizado, é iniciado pela ativação de neurônios serotoninérgicos da rafe no tronco encefálico, que inibem a transmissão de impulsos sensoriais para o córtex cerebral, diretamente, ou através do tálamo, assim como inibem a atividade motora. A transmissão sináptica através do tálamo é obliterada durante a sonolência e bloqueada no sono de ondas lentas. Neurotransmissores como a adenosina e o GABA (ácido gama-amino-butírico), os opióides endógenos, a somatostatina e o hormônio alfa-melanocítico-estimulante facilitam o sono NREM. Neurônios que contêm adenosina, situados no hipotálamo, são sensíveis a bloqueadores do receptor de adenosina, como a cafeína e as xantinas, que atuam inibindo o sono. Os benzodiazepínicos ligam-se a receptores gabaérgicos pós-sinápticos, facilitando o sono NREM.

O sono REM é caracterizado por uma cascata de fenômenos, desencadeados principalmente na porção lateral do núcleo reticular pontino oral, situado ventralmente ao locus ceruleus (área peri-locusceruleus). No sono REM, a inibição talâmica sobre o córtex é revertida, como na vigília, gerando o padrão dessincronizado no EEG. Neurônios da área perilocus-ceruleus estimulam células inibitórias do núcleo reticular magnocelular da ponte que, através do trato tegmento-reticular, inibem os motoneurônios medulares, causando a atonia muscular. A rede de neurônios do tronco encefálico que promovem a inibição do tono muscular no sono REM usa acetilcolina e glutamato como seus principais neurotransmissores.

A ativação de neurônios das porções dorso-laterais da ponte, adjacentes ao braço conjuntivo, conhecida como área peribraqueal $\mathrm{X}$, estimula a produção de potenciais elétricos no corpo geniculado lateral, relacionados com funções visuais, e no córtex cerebral, principalmente occipital. Este sistema, relacionado com a produção de potenciais elétricos conhecidos como ondas ponto-geniculo-occipitais, parece estar envolvido na produção dos movimentos oculares rápidos e na geração do conteúdo visual dos sonhos.

A complexidade dos sistemas encefálicos geradores da vigília e dos sonos NREM e REM ainda vem sendo elucidada através de pesquisa básica e os dados acima citados fornecem apenas uma visão simplista do conhecimento atual sobre os centros encefálicos controladores do sono e da vigília ${ }^{11,12}$.

Fernandes RMF. The normal sleep. Medicina (Ribeirão Preto) 2006; 39 (2): 157-168.

ABSTRACT: Sleep is a cyclic state characterized in the human being by 5 fundamental stages, based on the electroencephalogram (EEG) pattern and the presence or absence of rapid eye movements (REM), as well as changes in other physiologic variables, like muscle tonus and cardio-respiratory pattern. The EEG shows progressive slowing with the deepening of the sleep without rapid eye movements (Non-REM) which evolves into REM sleep each 90 minutes during night sleep, comprising a predictable nocturnal sleep architecture, with definite proportions of each sleep stage. A neurochemical bio-rhythm follows sleep-wake cycle, with changes in body temperature and variations in the secretion pattern of neurotransmitters and hormones, related to different stages of sleep and wakefulness. The knowledge about physiological features and pathological variations of this complex cycle has enabled the development of Sleep Medicine and has given basis to the study of sleep disorders.

Keywords: Sleep; physiology. Sleep Stages. Sleep, REM. Circadian Rhythm. Eye Movements. 


\section{REFERÊNCIA}

1 - Niedermeyer E. Historical aspects. In: Niedermeyer E, Silva $\mathrm{FL}$, eds. Electroencephalography, basic principles, clinical applications and related fields. $5^{\text {th }}$ ed. Baltimore: Lippincot Williams \& Wilkins; 2005. p. 1-15.

2 - Dement WC. History of sleep physiology and medicine. In: Kryger MH, Roth T, Dement WC, eds. Principles and practice of sleep medicine. $4^{\text {th }}$ ed. Philadelphia: Elsevier Saunders; 2005. p. 1-12.

3 - Aserinsky E, Kleitman N. Regularly occurring periods of eye motility, and concomitant phenomena, during sleep. Science 1953; 118: 273-4.

4 - Aserinsky E, Kleitman N. Two types of ocular motility occurring in sleep. J Appl Physiol 1955; 8: 11-8.

5 - Dement W, Kleitman N. Cyclic variations in EEG during sleep and their relation to eye movements, body motility, and dreaming. Electroencephalogr Clin Neurophysiol 1957; 9: 673-90.

6 - Gastaut H, Tassinari C, Duron B. Étude polygraphique des manifestations episodiques (hypniques et respiratoires) du syndrome de Pickwick. Rev Neurol 1965; 112: 568-79.
7 - Jung R, Kuhlo W. Neurophysiological studies of abnormal night sleep and pickwickian syndrome. Prog Brain Res 1965; 18: $140-59$.

8 - Diagnostic Classification Steering Committe. International Classification of Sleep Disorders. Diagnostic and Coding Manual. Rochester, Minn.: American Sleep Disorders Association; 1990.

9 - American Sleep Disorders Association. International Classification of Sleep Disorders. Diagnostic and Coding Manual, Revised. Rochester, Minn.: American Sleep Disorders Association; 1997.

10 - American Academy of Sleep Medicine. International Classification of Sleep Disorders: Diagnostic and Coding Manual, $2^{\text {nd }}$ ed. Westchester, III: American Academy of Sleep Medicine; 2005.

11 - Culebras A. The biology of sleep. In: Culebras A, ed. Clinical handbook of sleep disorders. Oxford: ButterworthHeinemann, 1996. p. 13-5.

12 - Jones BE. Brain mechanisms of sleep-wake states. In: Kryger $\mathrm{MH}$, Roth T, Dement WC, eds. Principles and practice of sleep medicine. $4^{\text {th }}$ ed. Philadelphia: Elsevier Saunders; 2005. p 136-53. 